\title{
Effect of glucocorticoid therapy on bones in children with congenital adrenal hyperplasia: A Sri Lankan experience
}

\author{
*KSH de Silva ${ }^{1}$, US Hewagamage ${ }^{2}$, P Wickramarachchi ${ }^{3}$, A Weerasinghe ${ }^{4}$, Gaya Katulanda $^{5}$, \\ SN Seneviratne ${ }^{6}$, MW Gunathunga ${ }^{7}$
}

Sri Lanka Journal of Child Health, 2019; 48(1): 47-52

\begin{abstract}
Introduction: Congenital adrenal hyperplasia $(\mathrm{CAH})$ requires lifelong glucocorticoid therapy (GCT). Long- term use of GCT is known to adversely affect bone metabolism. Vitamin D synthesis in the skin can be impaired by the hyperpigmentation seen in $\mathrm{CAH}$ patients.
\end{abstract}

Objectives: To describe the effects of glucocorticoid therapy and vitamin $\mathrm{D}$ status on the bones in children with $\mathrm{CAH}$.

Method: Children with $\mathrm{CAH}$ followed up in the University Unit at the Lady Ridgeway Hospital, Colombo were studied. Mean values of the daily dose of hydrocortisone received, serum calcium, intact parathormone (iPTH) and 25-hydroxy vitamin D levels were compared with the duration of therapy categorized into 3 groups. Skin pigmentation was graded using the Fitzpatrick scale and was described with the biochemical parameters according to vitamin D status (sufficiency $>50 \mathrm{nmol} / \mathrm{L}$ ).

Results: Thirty eight children were studied. Mean daily dose of hydrocortisone of children treated for less than 4 years $(n=6), 4$ to 7 years $(n=6)$ and more than 7 years $(n=26)$ were $14.0,13.4$, and 14.0 $\mathrm{mg} / \mathrm{m}^{2} /$ day respectively (recommended dose $10-15$

${ }^{1}$ Professor in Paediatrics, Faculty of Medicine, University of Colombo, ${ }^{2}$ House Officer, Castle Street Maternity Hospital, Colombo, ${ }^{3}$ Relief House Officer, Karapitiya Teaching Hospital, Galle, ${ }^{4}$ Relief House Officer, De Soysa Hospital for Women, Colombo, ${ }^{5}$ Consultant Chemical Pathologist, Medical Research Institute, Colombo, ${ }^{6}$ Consultant Endocrinologist and Senior Lecturer in Paediatrics, Faculty of Medicine, University of Colombo, ${ }^{7}$ Professor in Community Medicine, Faculty of Medicine, University of Colombo

*Correspondence: shamyadesilva@hotmail.com

(Received on 01 May, 2018; Accepted after revision on 29 June 2018)

The authors declare that there are no conflicts of interest

Personal funding was used for the project.

Open Access Article published under the Creative

Commons Attribution CC-BY (c) (†) License $\mathrm{mg} / \mathrm{m}^{2} /$ day). Mean serum calcium levels (2.53, $2.41,2.28 \mathrm{mmol} / \mathrm{L})$ and iPTH levels $(3.59,4.46$, $6.30 \mathrm{pmol} / \mathrm{L})$ were in the normal range and vitamin D levels $(47.55,47.97,44.44 \mathrm{nmol} / \mathrm{L})$ were in the insufficient range. The differences between the groups were not significant. However, the difference seen in alkaline phosphatase (ALP) was significant $(p=0.026)$. There was also an apparent inverse association of ALP with the total average daily dose of glucocorticoids $\left(\mathrm{R}^{2}=0.077, \mathrm{~F}=3.0\right.$, $\mathrm{p}=0.092)$. Vitamin D deficiency $(\leq 37.5 \mathrm{nmol} / \mathrm{L})$ was seen in $8(21.1 \%)$ patients. Degree of pigmentation and biochemical parameters assessed were not significant according to vitamin D status.

\section{Conclusions:}

Serum ALP levels show an inverse relationship with the duration of glucocorticoid therapy indicating possible adverse outcome on bones. The apparent inverse relationship of total average daily dose of glucocorticoids with ALP failed to reach statistical significance. No relationship was found with vitamin $\mathrm{D}$ status and other parameters assessed.

DOI: http://dx.doi.org/10.4038/sljch.v48i1.8651

(Key words: Children with CAH, glucocorticoid therapy, effect on bones)

\section{Introduction}

Congenital adrenal hyperplasia (CAH) is commonly caused by deficiency of 21-hydroxylase resulting in impaired or absent cortisol and aldosterone synthesis ${ }^{1}$. Management of $\mathrm{CAH}$ requires lifelong glucocorticoid therapy at a dose ranging from $10-15 \mathrm{mg} / \mathrm{m}^{2} /$ day to prevent adrenal crises and suppress elevated ACTH thereby suppressing adrenal androgen overproduction ${ }^{1,2}$. Bone homeostasis is a balance between osteoblastic bone formation and osteoclastic bone resorption. Glucocorticoids stimulate osteoclastic bone resorption and reduce osteoblastic bone formation thereby altering bone homeostasis ${ }^{3,4}$. Steroid induced bone loss appears to be reversible ${ }^{5}$. Long term use causes an initial rapid reduction in the BMD due to bone resorption within the first 3 months of therapy with a maximum loss by 6 months followed by a slower progressive loss due to impaired bone formation ${ }^{2,5,6}$. Osteoporosis and a 
raised fracture risk are reported with long term glucocorticoid use in adults with $\mathrm{CAH}$ and rheumatoid arthritis ${ }^{2,5,6,7}$. However, the findings on the effects on children with $\mathrm{CAH}$ on long-term steroids are inconclusive with both normal BMD and low bone turnover being reported ${ }^{8,9,10,11}$.

A $51.9 \%$ prevalence of vitamin D deficiency has been shown in children with $\mathrm{CAH}^{12}$. The metabolically active 1, 25 dihydroxy vitamin D promotes mineralization of osteoid tissue ${ }^{3}$. Steroids promote formation of the inactive 24,25dihydroxy vitamin $\mathrm{D}$ and thus modify the effect of vitamin D on osteoblasts ${ }^{6}$. It has been recommended to measure vitamin D levels in children with $\mathrm{CAH}$ and supplementation offered for those with low levels ${ }^{11}$. Calcium and vitamin D supplementation has also been recommended for all patients on long-term glucocorticoid therapy $y^{2,5,6,7}$.

The effect of GCT and vitamin D status on bone metabolism in children with $\mathrm{CAH}$ has not been previously reported from Sri Lanka, thus justifying the present study.

\section{Objectives}

To describe the effect of glucocorticoid therapy and vitamin D status on the bones in children with $\mathrm{CAH}$.

\section{Method}

All the children with $\mathrm{CAH}$ (both salt wasting and non-salt wasting) followed up at the University Paediatric Unit at Lady Ridgeway Hospital (LRH), Colombo, were invited to participate in the study. The study was confined to the patients of only one ward to ensure uniformity of management. Children who have been on vitamin D preparations and calcium supplements were excluded from participation. The socio-demographic data were obtained through an interviewer-administered questionnaire. A sample of blood was taken at $8 \mathrm{am}$ following a 4-6 hour fast for estimation of the bone profile [serum calcium, serum phosphate and alkaline phosphates (ALP)], intact parathormone (iPTH) levels and 25-hydroxy vitamin D.

Children with $\mathrm{CAH}$ are treated from the moment of diagnosis of the condition, usually in the neonatal period. Since all the patients were invited for the study, the duration of treatment was variable and therefore was categorized as less than 4 years, 4-7 years and more than 7 years. The mean (SD) cumulative dose of hydrocortisone they have been on for the total duration of therapy was calculated. 25-hydroxy vitamin D (which includes both D2 and D3) was assayed using the chemiluminescent micro-particle immunoassay (Abbott Architect 1000i SR system). Vitamin D deficiency was defined as a value $\leq 37.5 \mathrm{nmol} / \mathrm{L}$, insufficiency as $>37.5-50.0 \mathrm{nmol} / \mathrm{L}$ and sufficiency as $>50$ $250 \mathrm{nmol} / \mathrm{L}^{13}$. Vitamin D synthesis in the skin may be impaired due to the hyper-pigmentation seen in patients with CAH. Therefore their skin pigmentation was assessed using the Fitzpatrick scale $^{14}$ where pigmentation is graded from 1 to 6 based on progressive increase in the pigmentation.

The biochemical parameters were compared with the duration of therapy, mean (SD) dose of hydrocortisone and the vitamin D status. The facility to do bone densitometry on the patients was not available at Lady Ridgeway Hospital at the time of the study. The study was performed over 6 months from August 2016. Ethical clearance was obtained from the Ethics Review Committees of the Faculty of Medicine, University of Colombo and the Lady Ridgeway Hospital, Colombo.

\section{Results}

All 38 patients who were invited participated in the study. There were 3 pairs of siblings. None of them had been on vitamin D preparations or calcium supplements. Socio-demographic characteristics of the study sample are shown in Table 1.

Table 1

Socio-demographic characteristics of study sample $(n=38)$

\begin{tabular}{|l|c|}
\hline \multicolumn{1}{|c|}{ Characteristic } & Number (\%) \\
\hline Age (years) & $21(55.2)$ \\
Less than 10 & $11(29.0)$ \\
$10-14$ & $06(15.8)$ \\
15 and above & $10(26.3)$ \\
\hline Sex & $28(73.7)$ \\
Male & \\
Female & $25(65.8)$ \\
\hline Ethnicity & $05(13.2)$ \\
Sinhalese & $05(13.2)$ \\
Indian Tamil & $03(07.9)$ \\
Sri Lankan Tamil & \\
Muslim & $12(31.6)$ \\
\hline Family income (Rupees) & $12(31.6)$ \\
10,000 - 20,000 & $05(13.2)$ \\
20,001 - 30,000 & $01(02.6)$ \\
30,001 - 40,000 & $01(02.6)$ \\
40,001 - 50,000 & $07(18.4)$ \\
50,001 - 60,000 & \\
Above 60,000 & $20(52.6)$ \\
\hline Province of residence & $08(21.1)$ \\
Western & $04(10.5)$ \\
North Western & $02(05.3)$ \\
Sabaragamuwa & $04(10.5)$ \\
Central & \\
Other & \\
\hline
\end{tabular}

Twenty one $(55.2 \%)$ of the study sample were less than 10 years of age and $28(73.7 \%)$ were female. 
Twenty five (65.8) were Sinhalese. The parents of $29(76.4 \%)$ had a monthly income of 40,000 rupees or less. The majority $(52.6 \%)$ of the patients were from the Western Province (Table 1).
The mean daily doses of hydrocortisone, serum calcium corrected for serum albumin, serum ALP, iPTH and vitamin D level corresponding to the durations of therapy are given in Table 2 .

Table 2: Description of the biochemical and pharmacological parameters with duration of therapy (n=38)

\begin{tabular}{|l|c|c|c|c|c|}
\hline $\begin{array}{l}\text { Duration of } \\
\text { glucocorticoid } \\
\text { treatment }\end{array}$ & $\begin{array}{c}\text { Hydrocortisone } \\
\text { dose/day } \\
\text { mean (SD) }\end{array}$ & $\begin{array}{c}\text { Corrected serum } \\
\text { calcium } \\
\text { mean (SD) } \\
(\mathrm{n} \rightarrow 2.2-2.7 \mathrm{mmol} / \mathrm{L})\end{array}$ & $\begin{array}{c}\text { Alkaline } \\
\text { phosphatase } \\
\text { mean (SD) } \\
(\mathrm{n} \rightarrow 60-425 \mathrm{U} / \mathrm{L})\end{array}$ & $\begin{array}{c}\text { iPTH } \\
\text { mean (SD) } \\
(\mathrm{n} \rightarrow 1.59- \\
7.21 \mathrm{pmol} / \mathrm{L})\end{array}$ & $\begin{array}{c}\text { *Vitamin D } \\
\text { level } \\
(\mathrm{nmmol} / \mathrm{L})\end{array}$ \\
\hline$<4$ years $(n=6)$ & 14.0 & 2.53 & 282 & 3.59 & 47.55 \\
$(2.3)$ & $(38)$ & 171 & 4.46 & 47.97 \\
\hline $4-7$ years $(n=6)$ & $(3.9)$ & 2.41 & $(55)$ & $(2.22)$ & $(23.16)$ \\
\hline$>7$ years $(\mathrm{n}=26)$ & $(4.9)$ & $(0.18)$ & $(95)$ & 6.3 & 44.44 \\
& 14.0 & 2.28 & 0.026 & 0.175 & 0.874 \\
\hline $\begin{array}{l}p \text { value for } \\
\text { independent sample } \\
\text { median test }\end{array}$ & $(5.4)$ & 0.194 & $(125)$ & & \\
\hline
\end{tabular}

*Vitamin D status ${ }^{13}:$ Deficient $\leq 37.5$ nmol/L, Insufficient $>37.5-50.0 \mathrm{nmol} / \mathrm{L}$, Sufficient $>50.0-250.0 \mathrm{nmol} / \mathrm{L}$

The mean (SD) daily dose of hydrocortisone was in the recommended dose range of $10-15 \mathrm{mg} / \mathrm{m}^{2} /$ day in all three groups. The apparent reduction and increase seen in serum calcium and $\mathrm{iPTH}$ respectively over time was not significant. However, the reduction seen in ALP was significant $(p=0.026)$. Vitamin D levels in all 3 groups were in the insufficient range. The average total dose of glucocorticoids in the individual patients ranged from 8.69 to 37.4 with a mean (SD) of 13.88 (5.02).

In regression analysis between total dose of glucocorticoids in the individual patients and bone health indicators, there were no significant associations (iPTH $\mathrm{R}^{2}=0.003, \mathrm{~F}=0.961, p=0.761$; Total $\mathrm{Ca} \mathrm{R}^{2}=0.003, \mathrm{~F}=0.113, p=0.768$ ). However, ALP showed an inverse relationship with the total dose of glucocorticoids with a coefficient of determination of $0.077, \mathrm{~F}=3.0$ and a significance of 0.092 , though not reaching $95 \%$ confidence level (Figure 1).

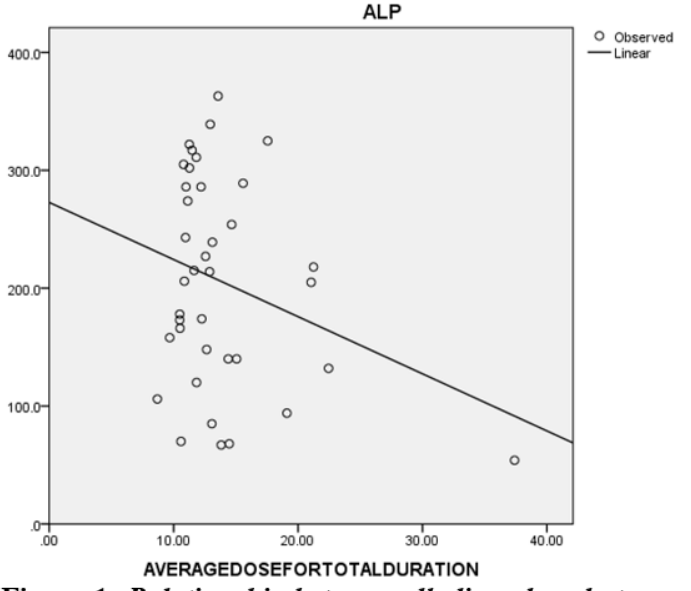

Figure 1: Relationship between alkaline phosphatase (ALP) and average dose of glucocorticoids for total duration of treatment $\mathrm{R}^{2}=0.077, \mathrm{~F}=3.0, \mathrm{P}=0.092$

Vitamin D deficiency $(\leq 37.5 \mathrm{nmol} / \mathrm{L})$ was seen in 8 $(21.1 \%)$ patients. Table 3 gives the biochemical parameters and the degree of pigmentation in relation to the vitamin $\mathrm{D}$ status. There was no significant association of the parameters assessed with the vitamin D status.

Table 3: Description of biochemical parameters and degree of pigmentation with vitamin D status $(n=38)$

\begin{tabular}{|l|c|c|c|c|}
\hline \multicolumn{1}{|c|}{ Vitamin D status } & $\begin{array}{c}\text { Corrected serum } \\
\text { calcium } \\
\text { mean (SD) } \\
(\mathbf{n} \rightarrow \mathbf{2 . 2 - 2 . 7 m m o l} / \mathbf{L})\end{array}$ & $\begin{array}{c}\text { Alkaline } \\
\text { phosphatase } \\
\text { mean (SD) } \\
(\mathbf{n \rightarrow 6 0 - 4 2 5} \mathbf{~ U / L )}\end{array}$ & $\begin{array}{c}\text { iPTH } \\
\text { mean (SD) } \\
\mathbf{( n \rightarrow 1 . 5 9 -} \\
\mathbf{7 . 2 1} \mathbf{6 m o l} / \mathbf{L})\end{array}$ & $\begin{array}{c}\text { Mean } \\
\text { Fitzpatrick score }\end{array}$ \\
\hline $\begin{array}{l}\text { Vitamin D deficient and } \\
\text { insufficient }(n=23)\end{array}$ & $2.35(0.28)$ & $195.95(89.2)$ & $5.72(2.5)$ & $4.3(0.98)$ \\
\hline Vitamin D sufficient $(n=15)$ & $2.34(0.38)$ & $220.4(88.8)$ & $5.36(5.0)$ & $4.46(0.64)$ \\
\hline Student test value & 0.088 & 0.828 & 0.256 & 0.61 \\
\hline$p$ value & 0.53 & 0.20 & 0.60 & 0.27 \\
\hline
\end{tabular}

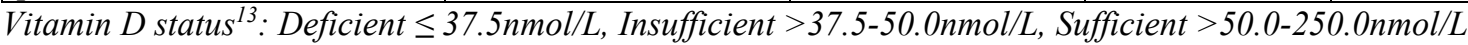




\section{Discussion}

Bone remodelling is a constant process due to bone resorption and formation by osteoclasts and osteoblasts respectively ${ }^{3}$. ALP is released during bone formation by osteoblasts ${ }^{3}$. 7-Dehydrocholesterol in the skin is converted to vitamin D3 (cholecalciferol) by a process triggered by ultraviolet light and is finally converted in the kidney to 1,25-dihydroxy Vitamin $\mathrm{D}^{3}$, which maintains serum calcium in the normal range by its action on the intestine, kidneys and bone ${ }^{3}$. Thus, hypocalcaemia caused by vitamin D deficiency gives rise to secondary hyperparathyroidism, which in turn stimulates osteoclastic activity mobilizing calcium from bones ${ }^{3}$.

Long-term glucocorticoid use can result in osteoporosis with decreased bone mineral density (BMD) by decreasing bone formation by inhibiting osteoblastic activity and stimulating osteoclastic activity $^{8}$. It also stimulates formation of the inactive 24, 25-dihydroxy Vitamin D3, thus contributing to a reduction in the serum calcium ${ }^{6}$. BMD being the measure of mineralization of bones, is ideally assessed with Dual Energy X-ray Absorptiometry $(\mathrm{DXA})^{2,4,15}$. Bone turnover markers could be measured as serum osteocalcin and pro-collagen peptide being markers of bone formation and bone resorption markers as serum $\mathrm{C}$-terminal telopeptide and urinary amino-terminal telopeptide ${ }^{8,9}$. The facilities to do these investigations are not available at the Lady Ridgeway Hospital. Therefore, we measured the serum calcium, ALP and IPTH with vitamin $\mathrm{D}$ to assess the effect of therapy on the bones.

This study was done with patients attending the University Paediatric Unit and available resources. Though it was more appropriate to involve more units our sample included children from seven out of nine provinces indicating island wide distribution. As we invited all the children with CAH to participate we did not calculate a sample size. However, a bigger sample size would have given more conclusive results.

There was a significant decrease in ALP $(p=0.026)$ with increasing duration of treatment indicating possible reduction in bone formation with glucocorticoid therapy. Relationship with the average dose for total duration appears to be similar though it failed to reach statistical significance at the $95 \%$ confidence level. This observation is probably due to higher than the recommended doses of glucocorticoids given to some children. These findings are in line with the already known effects of glucocorticoid therapy. There was also an apparent reduction seen in serum calcium and an increase in serum iPTH over time, but maintaining within the normal range, with continued therapy but this finding was not statistically significant. If the serum and urinary bone turnover markers could have been measured and DXA scans performed, the findings may have complemented the observations of our study.

Pigmentation impairs synthesis of vitamin D in the skin and this effect is known to increase with increasing skin pigmentation ${ }^{14}$. In our study, the corrected serum calcium, alkaline phosphatase, iPTH and Fitzpatrick score did not vary significantly with the vitamin D status. This is probably because the mean vitamin $\mathrm{D}$ levels did not show much variation between the sufficient group and deficient-insufficient group (58.33 (SD7.74) and 37.44 (SD-10.27) respectively) to generate changes in other biochemical parameters. Fitzpatrick score, hence pigmentation, also showed insignificant variation between the two levels of vitamin D partly explaining the lack of variation in the values of vitamin D. Moreover, there are other factors, such as glucocorticoid therapy, that modify the relationship between vitamin D and the other biochemical parameters.

A vitamin D level of $\leq 50 \mathrm{nmol} / \mathrm{L}$ (deficiency and insufficiency) was seen in $23(60.5 \%)$ of our patients and none of them were on calcium or vitamin D supplements. However, we did not analyse the intake of calcium and vitamin D in the diet and we did not record the 17OHP and DHEAS levels as indicators of adequacy of glucocorticoid therapy, which are limitations of our study. We endorse that all measures should be taken to treat children with $\mathrm{CAH}$ within the recommended dose range. Glucocorticoid therapy in $\mathrm{CAH}$ being lifelong, improving the dietary intake and supplementing with calcium and vitamin $\mathrm{D}$ is advisable.

\section{Conclusions}

Serum ALP levels show an inverse relationship with the duration of therapy and also with the total average daily dose of glucocorticoids, though not reaching 95\% significance level indicating possible adverse outcome on bones in children with $\mathrm{CAH}$. No relationship was found with vitamin D status and the other parameters assessed.

\section{References}

1. Speiser PW, Azziz R, Baskin LS, Ghizzoni L, Hensle TW, Merke DP et al. Congenital adrenal hyperplasia due to steroid 21-hydroxylase deficiency: An Endocrine Society Clinical Practice Guideline. Journal of Clinical 
Endocrinology and Metabolism 2010; 95(9): 4133-60.

https://doi.org/10.1210/jc.2009-2631

PMid: 20823466 PMCid: PMC2936060

2. Falhammar H, Filipsson H, Holmdahl G, Janson P, Nordenskjold A, Hagenfeldt K et al. Fractures and bone mineral density in adult women with 21-hydroxylase deficiency. Journal of Clinical Endocrinology and Metabolism 2007; 92(12):4643-9.

https://doi.org/10.1210/jc.2007-0744

PMid: 17878254

3. Hormonal control of calcium metabolism and physiology of Bone. In: Review of Medical Physiology. William F Ganong 1995; 17th edition. Prentice-Hall International Inc. Appleton and Lange

4. Freire POdeA, De Lemos-Marini SHV, Maciel-Guerra AT, Morcillo AM, Baptista MTM, De Mello MP et al. Classical congenital adrenal hyperplasia due to 21hydroxylase deficiency: a cross-sectional study of factors involved in bone mineral density. Journal of Bone and Mineral Metabolism 2003; 21:396-401. https://doi.org/10.1007/s00774-003-04346

PMid: 14586796

5. Grossman JM, Gordon R, Ranganath VK, Deal C, Caplan L, Chen W et al. American College of Rheumatology 2010 recommendations for the prevention and treatment of glucocorticoid-induced osteoporosis. Arthritis Care and Research 2010; 62(11):1515-26.

https://doi.org/10.1002/acr.20295

PMid: 20662044

6. Jehle PM. Steroid-induced osteoporosis: how can it be avoided? Nephrology Dialysis Transplantation 2003; 18: 861-4. https://doi.org/10.1093/ndt/gfg067 PMid: 12686653

7. Buckley LM, Leib ES, Cartularo KS, Vacek PM, Cooper SM. Calcium and vitamin D3 supplementation prevents bone loss in the spine secondary to lowdose corticosteroids in patients with rheumatoid arthritis. A randomized, double-blind, placebo-controlled trial. Annals of Internal Medicine 1996; 125(12): 961-8. https://doi.org/10.7326/0003-4819-12512-199612150-00004

8. Girgis R, Winter JSD. The effects of glucocorticoid replacement therapy on growth, bone mineral density and bone turnover markers in children with congenital adrenal hyperplasia. Journal of Clinical Endocrinology and Metabolism 1997; 82(12):3926-9.

https://doi.org/10.1210/jcem.82.12.4320

PMid: 9398689

9. Dayem SMAE, Anwar GM, Salama H, Kamel AF, Emara N. Bone mineral density, bone turnover markers, lean mass and fat mass in Egyptian children with congenital adrenal hyperplasia. Archives of Medical Science 2010; 6(1):104-10. https://doi.org/10.5114/aoms.2010.13516 PMid: 22371729 PMCid: PMC3278952

10. Cameron FJ, Kaymakci B, Byrt EA, Ebeling PR, Warne GL, Wark JD. Bone mineral density and body composition in congenital adrenal hyperplasia. Journal of Clinical Endocrinology and Metabolism 1995; 80(7):2238-43.

https://doi.org/10.1210/jc.80.7.2238

11. Okten A, Cakir M, Makuloglu M. Bone mineral status, bone turnover markers and vitamin D status in children with congenital adrenal hyperplasia. Minerva Endocrinologica 2012; 37(3):275-82.

PMid: 22766894

12. Migeon CJ, Wisniewski AB. Congenital adrenal hyperplasia owing to 21hydroxylase deficiency: growth, development and therapeutic considerations. Endocrinology and Metabolism Clinics of North America 2001; 30(1):193-206.

https://doi.org/10.1016/S08898529(08)70 026-4

13. Misra M, Pacaud D, Petryk A, CollettSolberg PF, Kappy M. Vitamin D deficiency in children and its management: Review of current knowledge and recommendations. Pediatrics 2008; 122(2):398-417. https://doi.org/10.1542/peds.2007-1894 PMid: 18676559 
14. Fitzpatrick TB. The validity and practicality of sun-reactive skin type I through VI (Editorial) Archives of Dermatology 1988; 124:869-71.

https://doi.org/10.1001/archderm.1988.01

670060015008

PMid: 3377516

15. Delvecchio M, Soldano L, Lonero A, Ventura A, Giordano P, Cavallo L et al. Evaluation of impact of steroid replacement treatment on bone health in children with 21-hydroxylase deficiency. Endocrine 2015; 48: 995-1000. https://doi.org/10.1007/s12020-014-03329

PMid: 24981037 